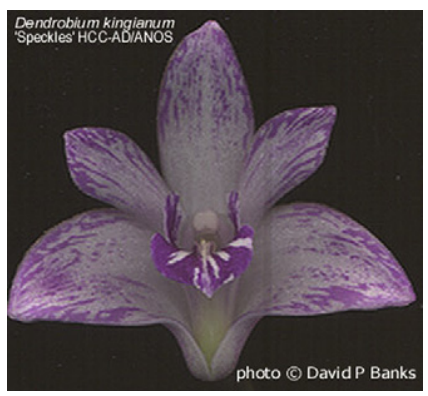

on an Overholt table, about to undergo a posterior thoracotomy and superior segmentectomy. Dr Overholt, 88 years old (approximately) at the time, comes into the room after scrubbing (only up to his wrists because of being cold; the head nurse would allow him to wear long-sleeved undershirts!). After him comes Dr Wilford Neptune, then about 68 years old, his "junior partner," to first assist. My role is to act as second assistant. In fact, it is to simply bear witness to this final historic operation with 2 giants in the field of thoracic surgery. Despite their advanced ages (combined, their age is almost 160 years!), their complete disregard for bleeding and anatomic challenges allows them to perform a standard posterior thoracotomy, cutting 3 ribs and allowing the blood to pool on the floor, in less than $1 \frac{1}{2}$ hours.

As I learned through the years from "Nep," as he was fondly referred to by his residents, he was a master surgeon who didn't crave the limelight.
"I remember when Charlie Bailey and I did the first..." was the beginning of many wonderful historical tales that he shared during the years I had the honor to train with him. At a time when most of his partners were doing standard open thoracotomies for esophagectomies, it was the elder Dr Neptune who taught us how to do transhiatal esophagectomies. I later learned that, much like my other mentor, Dr F. Henry (Bunky) Ellis, Jr, Nep had an illustrious career as a heart surgeon in addition to being a master thoracic surgeon. He was doing valvotomies and commisurotomies when most people were standing on the sidelines with this novel approach to mitral valve disease. He performed some of the earliest angiography in Boston, performing left heart catheterizations through a rigid bronchoscope with direct cannulation of the left atrium, and he did his share of the famed Vineberg operations with implantation of the internal thoracic artery onto the pericardium. In addition, he is credited by his family and residents with defining hemodilution as a method of safely using cardiopulmonary bypass.

Through it all, he was one of the kindest, gentlest and soft spoken of the giants that I had the privilege to work with. I well remember him visiting me when I was a junior fellow presenting a poster at the American College of Chest Physicians. He walked over and said hello to my wife, Diane, and our two little girls, beaming with pride as though he were their grandfather.

His caring for his residents and fellows probably was an offshoot of his caring for his orchids, which he did avidly throughout his life, even receiving numerous awards, among them one from the British Royal Horticultural Society. Between 2001 and 2008, Dr Neptune donated his entire orchid collection to Smith College, in Northampton, Massachusetts, where it will be used in teaching botany, landscape architecture, and art. It will also be part of the standing collection for public viewing, which currently receives 60,000 visits per year. Dr Neptune was an honorary member of the Massachusetts Orchid Society. $\mathrm{He}$ received a lifetime achievement award in 2000 from the Massachusetts Orchid Society and a similar award the following year from the Cape and Islands Orchid Society.

Dr Neptune will be sorely missed by the generations of Boston surgeons who had the privilege to work with him. We will long remember his humility, warmth and honesty.

Mark J. Krasna, MD Division of Thoracic Surgery St. Joseph's Medical Center Towson, $M d$ doi:10.1016/j.jtcvs.2010.11.041

\title{
Notice of Correction
}

Re: Wang J, Liu H, Xiang B, Li G, Gruwel M, Jackson M, Tomanek B, Salerno TA, Deslauriers R, Tian G. Keeping the heart empty and beating improves preservation of hypertrophied heart for valve surgery. J Thorac Cardiovasc Surg. 2006;132:1314-20.

In the above-noted article, the aortic banding period of pigs was inadvertently stated as 12 weeks. In fact, the aortic banding period was 8 weeks for induction of left ventricular hypertrophy in this study. The incorrect aortic banding period was stated in: (1) the first line in the section "Methods" in the abstract (p 1314); (2) the last line of the section "Pig Model of PressureOverloaded Left Ventricular Hypertrophy" in "Materials and Methods" (p 1315); (3) the first line in the section "Isolated Pig Heart Preparation" in "Materials and Methods" (p 1315); and (4) the second-to-last line in the section "Myocardial Hypertrophy" in "Results" ( $p$ 1317). The animals developed significant myocardial hypertrophy following 8 weeks of aortic banding. As a result, the above error does not affect the results and conclusion of the article. 